\title{
Continuous femoral nerve blockade and single-shot sciatic nerve block promotes better analgesia and lower bleeding for total knee arthroplasty compared to intrathecal morphine: a randomized trial
}

Nora Elizabeth Rojas Álvarez ${ }^{1 \dagger}$, Rosemberg Jairo Gomez Ledesma ${ }^{1 \dagger}$, Adilson Hamaji ${ }^{2}$, Marcelo Waldir Mian Hamaji ${ }^{2}$ and Joaquim Edson Vieira ${ }^{3^{*}}$

\begin{abstract}
Background: Knee arthroplasty leads to postoperative pain. This study compares analgesia and postoperative bleeding achieved by intrathecal morphine with a continuous femoral plus single-shot sciatic nerve block.

Methods: A randomized non-blinded clinical trial enrolled patients aged over 18 years old, ASA I to III who underwent total knee arthroplasty. All patients underwent spinal anesthesia with isobaric bupivacaine, $20 \mathrm{mg}$. One group received $100 \mathrm{mcg}$ of intrathecal morphine ( $\mathrm{M}$ group), and the other received a femoral nerve block by continuous infusion plus a "single shot" block of the sciatic nerve at the end of the surgery (FI group). Pain score from verbal numeric rating scale (VNRS) and morphine consumption during the first $72 \mathrm{~h}$, as well as motor blockade, adverse effects, and postoperative bleeding were recorded. Analysis of variance of repeated measures with Bonferroni post-test, $t$-test and Fisher exact test were used for statistical analysis.
\end{abstract}

Results: Thirty nine patients completed the study ( $M=20 ; \mathrm{Fl}=19$ patients) and were similar except for higher age in the Fl group. Motor blockade as well as movement pain during postanesthesia care unit (PACU) staying were not different between the groups, but movement pain was significantly lower in Fl group after $24 \mathrm{~h}$. Postoperative bleeding $(\mathrm{ml})$ was lower in $\mathrm{Fl}$ group.

Conclusions: Continuous femoral nerve block combined with sciatic nerve block provides effective for postoperative analgesia in patients undergoing total knee arthroplasty, with lower pain scores after $24 \mathrm{~h}$ and a lower incidence of adverse effects and bleeding compared to intrathecal morphine.

Trial registration: Retrospectively registered on https://clinicaltrials.gov/ under identifier NCT02882152, 23 $3^{\text {rd }}$ December, 2016.

Keywords: Analgesia, Nerve Block, Pain, Postoperative, Arthroplasty, Replacement, Knee, Anesthesia, Conduction

\footnotetext{
*Correspondence: joaquimev@usp.br

${ }^{\dagger}$ Equal contributors

${ }^{3}$ Department of Surgery, University of São Paulo Medical School, Av. Dr.

Arnaldo 455, sala 2345, Cerqueira César, São Paulo, SP, BrazilCEP 01246-903

Full list of author information is available at the end of the article
} 


\section{Background}

Knee arthroplasty leads to postoperative pain. Several techniques using regional anesthesia may provide effective analgesia and early recovery, as well as prevent thromboembolic events. A rapid rehabilitation allows higher patient satisfaction and lower costs [1].

Regional anesthesia is superior to general anesthesia with better postoperative pain control without the use of opioids and its adverse effects. For some operations, analgesia can be extended longer into the postoperative period by means of continuous infusions through epidural catheters [2]. In addition, spinal anesthesia plus opioids ensures quite effective analgesia, even though its side effects may delay the rehabilitation process $[3,4]$.

A meta-analysis of 185 patients suggested equivalent postoperative pain control comparing femoral nerve block and intrathecal morphine with fewer side effects with the femoral nerve blockade [5]. Continuous regional analgesia of the femoral nerve via a catheter may also extend analgesia in line with the patients' demands [6].

The sciatic nerve block is still controversial when it comes to analgesia for knee arthroplasty because this benefit is obtained at the expense of motor blockade of leg and foot, which functionally is of considerable importance during the immediate postoperative period [7].

This study compares analgesia achieved with intrathecal morphine administration to a continuous femoral block combined with a sciatic nerve block. Incidence of adverse effects, postoperative bleeding, patient's satisfaction and motor blockade of both techniques were also evaluated.

\section{Methods}

A randomized non-blinded prospective clinical trial conducted at the Institute of Orthopedics and Traumatology surgery, Hospital das Clinicas of University of São Paulo Medical School (IOT-HCFMUSP) in the period between December 2011 and September 2016. HCFMUSP Ethics Research Committee approved this study under number 0257/09, also registered on https://clinicaltrials.gov under identifier NCT02882152. Written informed consent to participate were obtained from all the participants.

After the signing of the informed consent, forty patients aged over 18 years old, ASA physical status from I to III (American Society of Anesthesiologists) who underwent total knee arthroplasty (TKA) were included and allocated by means of a random number table. Patients aged below 18 years old, with ASA IV or V physical status, infection near the puncture site, coagulation disorders, preexisting neurological disorders, allergy to local anesthetics, pregnancy and lactation, that refused spinal block or to sign an informed consent form were excluded from the study.
Patients were monitored with electrocardiography, noninvasive blood pressure and pulse oximetry. Hydration and type of fluid were at the discretion of the anesthesiologist. Sedation was performed with intravenous (IV) midazolam titrated doses (2-5 mg) and fentanyl (50-100 mcg). All patients underwent spinal anesthesia with $20 \mathrm{mg}$ of isobaric bupivacaine (Cristalia, São Paulo, Brazil). The patients were allocated into two groups: to receive $100 \mathrm{mcg}$ of intrathecal morphine (Cristalia, São Paulo, Brazil) (M group, $n=20$ ) or a femoral nerve block with insertion of a catheter for continuous infusion combined with a sciatic nerve block at the end of the surgery (FI group, $n=20$ ).

The femoral block used an 'out-of-plane' approach at the level of the inguinal ligament guided by ultrasound (FUJIFILM SonoSite, Bothell, United States) and by neurostimulation (BBraun, São Paulo, Brazil) to localize the nerve. Quadriceps contraction was obtained with an initial stimulation of $1 \mathrm{~mA}$ and then disappeared below a current level of $0.3 \mathrm{~mA}$. The needle's position was considered therefore adequate. After negative aspiration, $15 \mathrm{~mL}$ of ropivacaine at $0.5 \%$ Cristalia, São Paulo, Brazil) was injected. Ultrasound confirmed the dispersion of the solution within the iliac compartment. A catheter was inserted $5 \mathrm{~cm}$ beyond the tip of the needle without resistance. A continuous infusion was started using an elastomeric pump (B. Braun, easy pump, São Paulo, Brazil) filled with ropivacaine $0.2 \%$ at a rate of $5 \mathrm{ml} / \mathrm{h}$ for $48 \mathrm{~h}$. The Raj posterior approach directed the sciatic nerve block guided by ultrasound and neurostimulation until motor response with a current of $0.3 \mathrm{~mA}$. Following negative blood aspiration, a single injection of $15 \mathrm{ml}$ of $0.5 \%$ ropivacaine was given [8].

All patients received intraoperatively $2 \mathrm{~g}$ of dipyrone and $100 \mathrm{mg}$ of ketoprofen IV for analgesia and antiemetic prophylaxis with $8 \mathrm{mg}$ of ondansetron. Dipyrone 2 g every 6 hours and ketoprofen $100 \mathrm{mg}$ every $12 \mathrm{~h}$ were prescribed for postoperative pain at the anesthesiologists' discretion. Tramadol $100 \mathrm{mg}$ IV every 8 hours was offered as a rescue analgesia. If pain persisted with verbal numeric rating scale (VNRS) higher than 3 an infusion of morphine IV $2 \mathrm{mg}$ every $2 \mathrm{~h}$ was offered to lower VNRS $<3$.

Pain score from VNRS and morphine consumption during the first $72 \mathrm{~h}$ after surgery, as well as motor blockade, adverse effects, postoperative bleeding and patient satisfaction were all registered.

Evaluations were performed at post-anesthesia care unit (PACU) discharge and every $24 \mathrm{~h}$ up to $72 \mathrm{~h}$ after surgery. Pain intensity was evaluated by VNRS (zero = no pain, $1-3=$ mild pain, $4-5=$ moderate pain, $7-9=$ severe pain, $10=$ unbearable pain). The degree of patient satisfaction was qualified by a categorical scale ( $1=$ poor, 2 =fair, 3 =good; 4 =excellent). The degree of motor block was assessed on a Bromage scale (zero = 
no motor block, $1=$ can move the knee or foot, but cannot lift the leg, 2 = can only move the foot, 3 = cannot move the knee or foot). Adverse reactions such as nausea, vomiting, urinary retention, dyspnea and itching were registered.

The sample size was calculated to observe an effect size reduction of $25 \%$ for VNRS considering two groups and four moments (PACU, and 24, 48 and $72 \mathrm{~h}$ ), resulting in a total of 30 patients plus a dropout of up to $20 \%$ $(n=36)$, at a significance level of $5 \%$ and power of $90 \%$ [G*Power version 3.1.9.2. http://www.gpower.hhu.de/ en.html]. Demographic and monitoring data were compared with $t$-test or Fisher exact test. Morphine consumption, VNRS and Bromage results were compared by analysis of variance (ANOVA) of repeated measures followed by Bonferroni test. A significance level of 5\% was considered significant for a statistics power of $90 \%$.

\section{Results}

Thirty-nine patients completed the study (one dropout due to loss of medical records data in FI group; Fig. 1). The groups were similar except for age, higher in the FI group (Table 1).

There was no difference between the groups for pain in movement during PACU staying. After PACU discharge, pain intensity was significantly lower in the FI group (Table 2). Twenty percent of patients in M group required rescue analgesia with tramadol and 10\% with morphine.

Postoperative bleeding volume $(\mathrm{ml})$ was lower in the FI group at all times (Table 3). The motor blockade intensity showed no difference during PACU staying, but at $24 \mathrm{~h}$ four patients from the FI group showed a score of 1 and two scores of 2 (Bromage scale); at $48 \mathrm{~h}$ no patient had any motor blockade.

A majority of patients from the $\mathrm{M}$ group had pruritus as the main complaint in the PACU and in the first $24 \mathrm{~h}(n=$ $14,70 \%)$, followed by urinary retention $(n=10,50 \%)$, but not much nausea $(n=5,25 \%)$ and vomiting $(n=1,5 \%)$. No neurological complications, hematomas or systemic toxicity of the local anesthetic were observed in the FI group at any time. Patient satisfaction was excellent for FI at a rate of $100 \%$. In M group, $20 \%$ were completely satisfied, but an equal number found it a bad experience, mainly due to pain (Table 4).

\section{Discussion}

This study showed that continuous femoral block combined with sciatic nerve block provides better postoperative analgesia than intrathecal morphine for total knee arthroplasty.

In previous studies, intrathecal morphine has been considered more effective, except for pruritus, in comparison with femoral nerve block $[9,10]$. A low dose of intrathecal

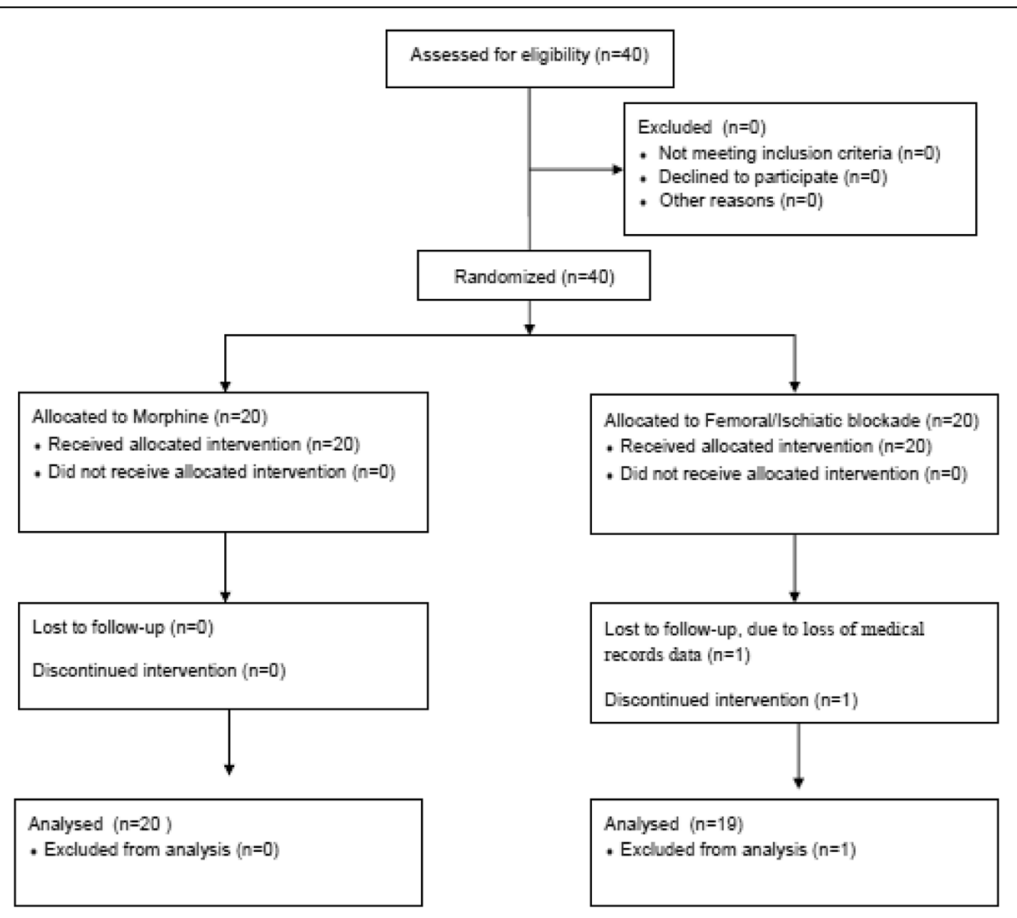

Fig. 1 Flowchart of eligibility and participation 
Table 1 Demographic and baseline values

\begin{tabular}{lccc}
\hline & \multicolumn{2}{l}{ Groups } & p-value \\
\cline { 2 - 3 } & Intratechal morphine & Femoral blockade & \\
\hline Age & $58.3 \pm 10.5$ & $67.3 \pm 8.3$ & $<0.01$ \\
Sex (F/M) & $14 / 6$ & $16 / 3$ & 0.45 \\
Weight & $77.5 \pm 16.9$ & $70.7 \pm 20.0$ & 0.25 \\
Systolic BP & $132.1 \pm 20.0$ & $136.2 \pm 22.9$ & 0.58 \\
Diastolic BP & $76.2 \pm 13.5$ & $72.1 \pm 21.1$ & 0.5 \\
HR & $72.5 \pm 9.4$ & $76.4 \pm 9.1$ & 0.2 \\
SatO2 & $96.3 \pm 1.5$ & $96.1 \pm 1.4$ & 0.62 \\
\hline
\end{tabular}

$B P$ Non-invasive Blood pressure, $H R$ heart rate, SatO2 oxygen saturation from pulse oximetry. All analysis using $t$ test (*significant), except for sex compared by means of Fisher exact test

morphine was considered safer than the femoral nerve blockade [11]. This study suggests, however, a better result for a femoral approach that may be due to a prolonged analgesia provided by a continuous blockade.

This continuous nerve block prolonged analgesia, reduced the consumption of rescue opioids as well as promoted early functional activity with no report of related accidental fall. The infusion pattern and location of the catheter were based on our clinical experience, but aimed to reach an analgesic quality under lower risk of nerve lesion [12]. One advantage of the femoral block for this surgery is the relaxing effect of the quadriceps muscles that provide greater tolerance to lower limb passive mobilization [13]. On the other hand, due to this muscle weakness, some authors consider it an independent risk factor for accidental fall in the postoperative period [14, 15]. Adductor canal block has been shown to preserve this muscle strength, but not enough to promote early mobilization and without a significant difference in postoperative pain $[16,17]$. More recently, a singleshot femoral blockade combined with low dose spinal anesthesia seemed as an alternative to conventional spinal anesthesia in outpatient arthroscopic meniscus repair [18].

Table 2 Assessment of pain during movement while in PACU, VNRS

\begin{tabular}{|c|c|c|c|c|}
\hline & \multicolumn{2}{|l|}{ Groups $(n)$} & \multirow{3}{*}{$\begin{array}{l}\text { Mean } \\
\text { difference }\end{array}$} & \multirow[t]{3}{*}{$p$-value } \\
\hline & $\begin{array}{l}\text { Intratechal } \\
\text { morphine }\end{array}$ & $\begin{array}{l}\text { Femoral } \\
\text { blockade }\end{array}$ & & \\
\hline & $M(n=20)$ & $\mathrm{FI}(n=19)$ & & \\
\hline PACU (zero) & $0.1 \pm 0.1$ & $0.0 \pm 0.0$ & $0.1 \pm 0.1$ & 0.30 \\
\hline $24 \mathrm{~h}$ & $3.0 \pm 0.5$ & $0.6 \pm 0.2$ & $2.3 \pm 0.5$ & $<0.01$ \\
\hline $48 \mathrm{~h}$ & $3.5 \pm 0.4$ & $0.3 \pm 0.1$ & $3.2 \pm 0.4$ & $<0.01$ \\
\hline $72 \mathrm{~h}$ & $2.6 \pm 0.3$ & $0.1 \pm 0.1$ & $2.5 \pm 0.3$ & $<0.01$ \\
\hline
\end{tabular}

ANOVA of repeated measures followed by Bonferroni test
Table 3 Postoperative bleeding volume in milliliters ( $\mathrm{ml}$ )

\begin{tabular}{|c|c|c|c|c|}
\hline & \multicolumn{2}{|l|}{ Groups (n) } & \multirow{3}{*}{$\begin{array}{l}\text { Mean } \\
\text { Difference }\end{array}$} & \multirow[t]{3}{*}{$p$-value } \\
\hline & $\begin{array}{l}\text { Intrathecal } \\
\text { morphine }\end{array}$ & $\begin{array}{l}\text { Femoral } \\
\text { blockade }\end{array}$ & & \\
\hline & $M(n=20)$ & $\mathrm{FI}(n=19)$ & & \\
\hline PACU (zero) & $271.8 \pm 33.3$ & $136.5 \pm 20.5$ & $135.3 \pm 39.1$ & 0.001 \\
\hline $24 \mathrm{~h}$ & $334.7 \pm 39.6$ & $180.5 \pm 19.7$ & $154.2 \pm 44.2$ & $<0.01$ \\
\hline $48 \mathrm{~h}$ & $111.9 \pm 28.4$ & $69.2 \pm 20.7$ & $42.6 \pm 35.2$ & $<0.01$ \\
\hline $72 \mathrm{~h}$ & $155.3 \pm 39.1$ & $20.0 \pm 0.0$ & $135.3 \pm 39.1$ & $<0.01$ \\
\hline
\end{tabular}

ANOVA of repeated measures followed by Bonferroni test

The sciatic nerve block remains controversial [19-21]. An inadequate sciatic nerve block may result in higher morphine consumption [10]. It seems to be useful in lateral arthroplasties due to the participation of some nerve fibers from peroneal innervation in this region [21]. Continuous sciatic nerve block combined with continuous femoral nerve block reduced consumption of opioids, the incidence of nausea and vomiting, and promoted better postoperative pain control in the $36 \mathrm{~h}$ immediately after TKA [22]. A systematic review, however, did not support these studies [20]. And femoral and sciatic nerve block promoted shorter hospital staying and superior postoperative pain control up to $12 \mathrm{~h}$ compared to femoral block plus local infiltration, even though local infiltration could preserve quadriceps function in the immediate postoperative period as an advantage [23-25].

The tendency to avoid sciatic block may be related to the risk of injury during TKA with an incidence ranging from 0.2 to $2.4 \%$. The main risk factors are valgus deformity, tourniquet's ischemia longer than $120 \mathrm{~min}$, pre-existing neuropathy and intraoperative bleeding [26]. This prolonged motor blockade can also hide an iatrogenic nerve injury [21]. The choice for the sciatic blockade in this study was to promote better analgesia by means of a considerable volume $(15 \mathrm{ml})$ of long duration local anesthetic (ropivacaine). No postsurgical neuropathy was observed.

Table 4 Adverse events frequency and satisfaction rate, at PACU and $24 \mathrm{~h}(\mathrm{~h})$ moments

\begin{tabular}{|c|c|c|c|c|c|}
\hline & \multicolumn{4}{|c|}{ Groups } & \multirow[t]{3}{*}{$p$-value } \\
\hline & \multicolumn{2}{|c|}{$\begin{array}{l}\text { Intratechal } \\
\text { morphine } \\
\text { M }(n=20)\end{array}$} & \multicolumn{2}{|c|}{$\begin{array}{l}\text { Femoral } \\
\text { blockade } \\
\text { FI }(n=19)\end{array}$} & \\
\hline & PACU & $24 \mathrm{~h}$ & $\overline{\mathrm{PACU}}$ & $\overline{24 \mathrm{~h}}$ & \\
\hline Pruritus & 14 & 7 & - & - & $<0.01^{*}$ \\
\hline Urinary retention & 10 & 7 & - & - & $<0.01^{*}$ \\
\hline Nausea & 5 & 6 & - & - & $<0.05^{* *}$ \\
\hline Vomiting & 1 & 3 & - & - & $>0.05$ \\
\hline Satisfaction (\%) at $24 \mathrm{~h}$ & 20 & & 100 & & $<0.05$ \\
\hline
\end{tabular}

*Significant for both moments of PACU and $24 \mathrm{~h}$ analysis at $p$-values $<0.01$ **significant for both moments of PACU and $24 \mathrm{~h}$ analysis at $p$-values $<0.05$. Fisher exact test 
The lower opioid consumption and consequent adverse effects such as nausea, vomiting, pruritus and urinary retention probably helped for the greater satisfaction, despite the more intense motor blockade. The results agree with a recent meta-analysis where sciatic and femoral blocks significantly reduce postoperative opioid consumption and reduce surgical pain compared to sole femoral nerve block [27]. Notwithstanding, a multimodal analgesia approach may provide the best results, even as further research is still needed [28].

Less postoperative bleeding occurred in the femoral group. Although there is no straightforward explanation, a hypothesis considers that greater motor blockade and better analgesia prompted less postoperative mobilization, as well as a possible vasoconstrictor effect of ropivacaine in continuous infusion [29].

Some limitations need to be considered. The use of a double variable, that is femoral catheter plus a sciatic blockade instead of only a continuous femoral block constrains the understanding that analgesia is mainly provided by a femoral block, and a third group would have addressed this issue. The study lacks blinding, which could have been accomplished by placing a catheter in the femoral nerve with placebo infusion to patients receiving intrathecal morphine, but this would be an increased risk of complications. Also, hospital staying or outcomes from physical therapy were not evaluated to observe the true impact of analgesia on postoperative recovery.

\section{Conclusions}

Continuous femoral nerve block combined with sciatic nerve block provides effective for postoperative analgesia in patients undergoing total knee arthroplasty, with lower pain scores after $24 \mathrm{~h}$ and a lower incidence of adverse effects and bleeding compared to intrathecal morphine.

\section{Abbreviations}

ANOVA: Analysis of variance; ASA: American Society of Anesthesiologists; Fl: Femoral infusion; HCFMUSP: Hospital das Clinicas of University of São Paulo Medical School; IOT-HCFMUSP: Institute of Orthopedics and Traumatology surgery, Hospital das Clinicas of University of São Paulo Medical School; IV: Intravenous; M: Morphine; PACU: Post-anesthesia care unit; TKA: Total knee arthroplasty; VNRS: Verbal numeric rating scale
\end{abstract}

\section{Acknowledgements}

The authors are grateful to the surgeons and anesthesiologists from the Instituto de Ortopedia e Traumatologia, Hospital das Clínicas da Faculdade de Medicina da Universidade de São Paulo who contributed to this study.

\section{Funding}

No funding has been used to sponsor this investigation. This work has been supported by Hospital das Clínicas - Universidade de São Paulo, Faculdade de Medicina (University of SP Medical School).

\section{Availability of data and materials}

The datasets used and analysed during the current study are available from the corresponding author on request.

\section{Authors' contributions}

NERA acquired patient data, prepared tables and contributed in writing the manuscript. RJGL acquired patient data, prepared tables and contributed in writing the manuscript. AH conceived and designed the study, acquired patient data and was a major contributor in writing the manuscript. MWMH supervised and helped to acquire patient data and contributed in writing the manuscript. JEV designed the study, analyzed and interpreted the data and was a major contributor in writing the manuscript. All authors read and approved the final manuscript.

\section{Authors' information}

NERA and RJGL are former residents in anesthesiology of the Anesthesiology Program at Faculdade de Medicina da Universidade de São Paulo; AH is anesthesiologist supervisor at Instituto de Ortopedia e Traumatologia, Hospital das Clínicas, MWMH is anesthesiologist at Instituto de Ortopedia e

Traumatologia, Hospital das Clínicas and JEV is associated professor of Anesthesiology at Faculdade de Medicina da Universidade de São Paulo.

\section{Competing interests}

The authors declare that they have no competing interests.

\section{Consent for publication}

Not applicable.

\section{Ethics approval and consent to participate}

HCFMUSP Ethics Research Committee approved this study under number 0257/09. An informed consent was presented to all patients prior to enrollment in the study groups. Written informed consent to participate were obtained from all the participants.

\section{Publisher's Note}

Springer Nature remains neutral with regard to jurisdictional claims in published maps and institutional affiliations.

\section{Author details}

${ }^{1}$ Hospital das Clínicas, Divisão de Anestesia, Rua Dr. Ovídio Pires de Campos, 471, Cerqueira César, São Paulo, SP, BrazilCEP 05403-010. ${ }^{2}$ Institute of Orthopedics and Trauma Surgery, Hospital das Clínicas, Rua Dr. Ovídio Pires de Campos, 333, Cerqueira César, São Paulo, SP, BrazilCEP 05403-010.

${ }^{3}$ Department of Surgery, University of São Paulo Medical School, Av. Dr. Arnaldo 455, sala 2345, Cerqueira César, São Paulo, SP, BrazilCEP 01246-903.

Received: 2 February 2017 Accepted: 8 May 2017

Published online: 12 May 2017

\section{References}

1. Bauer MC, Pogatzki-Zahn EM, Zahn PK. Regional analgesia techniques for total knee replacement. Curr Opin Anaesthesiol. 2014;27(5):501-6.

2. Guay J, Kopp S. Epidural pain relief versus systemic opioid-based pain relief for abdominal aortic surgery. Cochrane Database Syst Rev. 2016;1:CD005059. doi:10.1002/14651858.CD005059.pub4.

3. Bujedo BM, Santos SG, Azpiazu AU. A review of epidural and intrathecal opioids used in the management of postoperative pain. J Opioid Manag. 2012;8(3):177-92.

4. Gehling M, Tryba M. Risks and side-effects of intrathecal morphine combined with spinal anaesthesia: a meta-analysis. Anaesthesia. 2009:64(6):643-51.

5. Li XM, Huang CM, Zhong CF. Intrathecal morphine verse femoral nerve block for pain control in total knee arthroplasty: A meta-analysis from randomized control trials. Int J Surg. 2016;32:89-98.

6. Kadic L, Boonstra MC, DE Waal Malefijt MC, Lako SJ, VAN Egmond J, Driessen JJ. Continuous femoral nerve block after total knee arthroplasty? Acta Anaesthesiol Scand. 2009;53(7):914-20.

7. Grape S, Kirkham KR, Baeriswyl M, Albrecht E. The analgesic efficacy of sciatic nerve block in addition to femoral nerve block in patients undergoing total knee arthroplasty: a systematic review and meta-analysis. Anaesthesia 2016; doi: 10.1111/anae.13568

8. Raj PP, Parks RI, Watson TD, Jenkins MT. A new single-position supine approach to sciatic-femoral nerve block. Anesth Analg. 1975;54(4):489-93. 
9. Tarkkila P, Tuominen M, Huhtala J, Lindgren L. Comparison of intrathecal morphine and continuous femoral 3-in-1 block for pain after major knee surgery under spinal anaesthesia. Eur J Anaesthesiol. 1998;15(1):6-9.

10. Sites BD, Beach M, Gallagher JD, Jarrett RA, Sparks MB, Lundberg CJ. A single injection ultrasound-assisted femoral nerve block provides side effect-sparing analgesia when compared with intrathecal morphine in patients undergoing total knee arthroplasty. Anesth Analg. 2004;99(5):1539-43.

11. Frassanito L, Vergari A, Zanghi F, Messina A, Bitondo M, Antonelli M. Postoperative analgesia following total knee arthroplasty: comparison of lowdose intrathecal morphine and single-shot ultrasound-guided femoral nerve block: a randomized, single blinded, controlled study. Eur Rev Med Pharmacol Sci. 2010;14(7):589-96.

12. Chan EY, Fransen M, Parker DA, Assam PN, Chua N. Femoral nerve blocks for acute postoperative pain after knee replacement surgery. Cochrane Database Syst Rev. 2014;5:CD009941. doi:10.1002/14651858.CD009941.pub2.

13. Aguirre J, Del Moral A, Cobo I, Borgeat A, Blumenthal S. The role of continuous peripheral nerve blocks. Anesthesiol Res Pract. 2012;2012:560879.

14. Anastase DM, Cionac Florescu S, Munteanu AM, Ursu T, Stoica Cl. Analgesic techniques in hip and knee arthroplasty: from the daily practice to evidence-based medicine. Anesthesiol Res Pract. 2014;2014:569319.

15. Wasserstein D, Farlinger C, Brull R, Mahomed N, Gandhi R. Advanced age, obesity and continuous femoral nerve blockade are independent risk factors for inpatient falls after primary total knee arthroplasty. J Arthroplasty. 2013;28(7):1121-4.

16. Jæger P, Zaric D, Fomsgaard JS, Hilsted KL, Bjerregaard J, Gyrn J, Mathiesen O, Larsen TK, Dahl JB. Adductor canal block versus femoral nerve block for analgesia after total knee arthroplasty: a randomized, double-blind study. Reg Anesth Pain Med. 2013;38(6):526-32.

17. Wiesmann T, Piechowiak K, Duderstadt S, Haupt D, Schmitt J, Eschbach D, Feldmann C, Wulf H, Zoremba M, Steinfeldt T. Continuous adductor canal block versus continuous femoral nerve block after total knee arthroplasty for mobilisation capability and pain treatment: a randomised and blinded clinical trial. Arch Orthop Trauma Surg. 2016;136(3):397-406.

18. Turhan KS, Akmese R, Ozkan F, Okten FF. Comparison of low-dose spinal anesthesia and single-shot femoral block combination with conventional dose spinal anesthesia in outpatient arthroscopic meniscus repair. Eur Rev Med Pharmacol Sci. 2015;19(8):1489-97.

19. Cappelleri G, Ghisi D, Fanelli A, Albertin A, Somalvico F, Aldegheri G. Does continuous sciatic nerve block improve postoperative analgesia and early rehabilitation after total knee arthroplasty? A prospective, randomized, double-blinded study. Reg Anesth Pain Med. 2011;36(5):489-92.

20. Abdallah FW, Brull R. Is sciatic nerve block advantageous when combined with femoral nerve block for postoperative analgesia following total knee arthroplasty? A systematic review. Reg Anesth Pain Med. 2011;36(5):493-8.

21. Abdallah FW, Chan WW, Gandhi R, Koshkin A, Abbas S, Brull R. The analgesic effects of proximal, distal, or no sciatic nerve block on posterior knee pain after total knee arthroplasty: a double-blind placebo-controlled randomized trial. Anesthesiology. 2014;121(6):1302-10.

22. Pham Dang C, Gautheron E, Guilley J, Fernandez M, Waast D, Volteau C, Nguyen JM, Pinaud M. The value of adding sciatic block to continuous femoral block for analgesia after total knee replacement. Reg Anesth Pain Med. 2005;30(2):128-33.

23. Carvalho Júnior LH, Temponi EF, Paganini VO, Costa LP, Soares LF Gonçalves MB. Reducing the length of hospital stay after total knee arthroplasty: influence of femoral and sciatic nerve block. Rev Assoc Med Bras (1992). 2015;61(1):40-3.

24. Nagafuchi M, Sato T, Sakuma T, Uematsu A, Hayashi H, Tanikawa H, Okuma K, Hashiuchi A, Oshida J, Morisaki H. Femoral nerve block-sciatic nerve block vs. femoral nerve block-local infiltration analgesia for total knee arthroplasty: a randomized controlled trial. BMC Anesthesiol. 2015;15:182.

25. Hu B, Lin T, Yan SG, Tong SL, Yu JH, Xu JJ, Ying YM. Local Infiltration Analgesia Versus Regional Blockade for Postoperative Analgesia in Total Knee Arthroplasty: A Meta-analysis of Randomized Controlled Trials. Pain Physician. 2016;19(4):205-14.

26. Horlocker TT, Cabanela ME, Wedel DJ. Does postoperative epidural analgesia increase the risk of peroneal nerve palsy after total knee arthroplasty? Anesth Analg. 1994;79(3):495-500.
27. Abdallah FW, Madjdpour C, Brull R. Is sciatic nerve block advantageous when combined with femoral nerve block for postoperative analgesia following total knee arthroplasty? A meta-analysis. Can J Anaesth. 2016; 63(5):552-68.

28. Elmallah RK, Cherian JJ, Pierce TP, Jauregui JJ, Harwin SF, Mont MA. New and Common Perioperative Pain Management Techniques in Total Knee Arthroplasty. J Knee Surg. 2016;29(2):169-78.

29. Govêia CS, Magalhães E. Ropivacaine in peribulbar anesthesia vasoconstrictive properties. Rev Bras Anestesiol. 2010;60(5):495-512.

\section{Submit your next manuscript to BioMed Central and we will help you at every step:}

- We accept pre-submission inquiries

- Our selector tool helps you to find the most relevant journal

- We provide round the clock customer support

- Convenient online submission

- Thorough peer review

- Inclusion in PubMed and all major indexing services

- Maximum visibility for your research

Submit your manuscript at www.biomedcentral.com/submit 